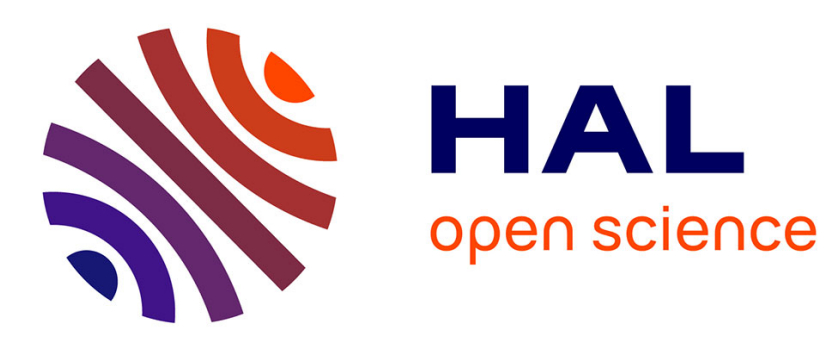

\title{
Elasto-plastic analysis of the interface behaviour between granular media and structure
}

\author{
Roger Frank, Vincenzo de Gennaro
}

\section{To cite this version:}

Roger Frank, Vincenzo de Gennaro. Elasto-plastic analysis of the interface behaviour between granular media and structure. Computers and Geotechnics, 2002, 29, No7, pp. 547-572. 10.1016/S0266352X(02)00010-1 . hal-00129509

\section{HAL Id: hal-00129509 \\ https://hal.science/hal-00129509}

Submitted on 7 Feb 2007

HAL is a multi-disciplinary open access archive for the deposit and dissemination of scientific research documents, whether they are published or not. The documents may come from teaching and research institutions in France or abroad, or from public or private research centers.
L'archive ouverte pluridisciplinaire HAL, est destinée au dépôt et à la diffusion de documents scientifiques de niveau recherche, publiés ou non, émanant des établissements d'enseignement et de recherche français ou étrangers, des laboratoires publics ou privés. 


\section{Elasto-plastic analysis of the interface behaviour between granular media and structure}

V. DE GENNARO ${ }^{(1)^{*}}$, R. FRANK ${ }^{(2)}$

(1) Ph.D., Research Fellow - CERMES (ENPC), Centre d'Enseignement et de Recherche en Mécanique des Sols - Ecole Nationale des Ponts et Chaussées, Paris (France)

(2) Professor - CERMES (ENPC), Centre d'Enseignement et de Recherche en Mécanique des Sols - Ecole Nationale des Ponts et Chaussées, Paris (France)

Paris, $19^{\text {th }}$ January 2002

\section{* Correspondence to:}

Dr. V. De Gennaro

CERMES (ENPC) - Centre d'Enseignement et de Recherche en Mécanique des Sols - Ecole Nationale des Ponts et Chaussées - 6 et 8 avenue Blaise Pascal - Cité Descartes - Champs-sur-Marne 77455

Marne-la-Vallée Cedex 2 - FRANCE

Tél.: ++331641535 52, Fax: ++331641535 62' e-mail: degennar@cermes.enpc.fr 


\title{
Elasto-plastic analysis of the interface behaviour between granular media and structure
}

V. De Gennaro \& R. Frank

\begin{abstract}
It is well known that interfaces usually play a major role in the definition of the mechanical behaviour of engineering structures having interactions with the soil. In this paper the general framework of an elasto-plastic constitutive model developed on purpose for describing the interface behaviour is presented. The model is based on a Mohr-Coulomb failure criterion, including deviatoric hardening/softening, phase transformation state (compaction and dilatancy) and ultimate state. The choice of the constitutive parameters and their identification is first discussed. The predictions of the model are then presented and compared with available experimental data from various interface tests between sand and metal plates. The results of the numerical analyses emphasise the key role played by the volumetric behaviour of the interface (compaction and dilatancy), linked in some cases with the change in the normal stress acting on the structure surface and, consequently, controlling the shear resistance at the interface.
\end{abstract}

Keywords: soil-structure interface, elasto-plasticity, constitutive law, interface testing, modelling 


\section{Introduction}

The serviceability of a wide range of engineering structures involving interfacing between structural elements and soil is highly dependent on the behaviour of the layer of soil forming close to the structure surface. Interfacing between bodies of different stiffness is also encountered in rock mechanics in systems of jointed and faulted rocks. In this case the zone of fracture is generally filled by granular materials, that are often the results of previous degradations of block surfaces. This layer, commonly referred to as the "interface", acts as a transition zone between the stiffer structural element and the softer soil medium or between the two rock blocks as well. In general this transition zone is mainly strained in the tangential direction. However, in granular materials, the volumetric behaviour of this layer is often complex, leading to compaction as well as dilatancy with displacement in the normal direction.

Probably the first complete and systematic experimental investigation of the interface behaviour has been presented by Potyondy [1]. In Potyondy's study experimental data are derived from tests performed with a modified direct shear box, obtained by replacing the half bottom part of the classical Casagrande direct shear box with a material simulating the structure. Various materials and different roughness have often been employed to highlight the factors controlling the interaction between the two media. This laboratory equipment (modified direct shear box) has been the object of several modifications, especially related to the possibility of reducing its principal deficiencies ([2] - [6]). In this respect it is worth noting that a wide range of increasingly sophisticated testing devices are available to date. Among others, let us quote: the pull out apparatus ([7]), the ring torsion apparatus ([8], [4], [9]), the simple shear apparatus ([10]) and more recently the cyclic three-dimensional simple shear interface apparatus ([11]), and the ring simple shear apparatus ([12], [13]). One basic phenomenological aspect is however common to all the apparatuses for interface testing: the 
observable kinematic state variables required for the description of the interface behaviour are the relative displacements, rather than deformations like as for a standard continuum medium. From a numerical viewpoint, a number of models have been presented recently for the description of the behaviour of interfaces. Most of them mainly concentrate on the behaviour of interfaces between granular soils and metal.

In a first class of models, on the basis of results concerning the modelling of rock joints, the material of the interface is supposed to be linear elastic, or non-linear with a stressdisplacement relationship of hyperbolic type in the normal and tangential directions ([14]). Hardening is not taken into account and the condition of failure, in terms of shear strength, is brought back to the traditional relation dictated by the Mohr-Coulomb failure criterion. More complex models, incorporating the concepts of dilatancy, compaction and damage, have been also proposed within this theoretical framework ([15] - [17]).

A second class refers to the theory of elasto-plasticity. Formulations relate as well to the assumptions of a perfect plasticity as to those of an hardening material (inter alia: [14], [18] [23]), permitting also the analysis of particular conditions such as cyclic loading and softening ([24] - [26]). Along with a new definition of the kinematic state variables, stresses are related to displacements, and the theoretical structure of these models remains identical to that of the majority of the elasto-plastic models suggested for the description of soil behaviour. Finally, also the use of polar continua ([27]) and of directionally dependent rate type laws ([28], [29]) has been attempted.

Given the results of previous studies already published in the literature, the research presented herein addresses the possibility to model in a unified and simple way the behaviour of an interface subjected to monotonic loading using a purposely developed elasto-plastic constitutive model. The model has direct links with the Mohr-Coulomb failure criterion, includes deviatoric hardening/softening behaviour, and integrates the phase transformation 
state (concept of compaction-dilatancy). An original treatment of the ultimate state condition at large tangential displacements (parallel to the direction of shear) is proposed, allowing to account for the modification of the granular assembly structure during shear. The choice of the constitutive parameters and their identification is discussed. The potential of such an approach to describe the response of a real interface is assessed through the comparisons of model predictions with various laboratory interface test results performed either at constant normal stress or at constant volume.

\section{The elasto-plastic stress-displacement law}

Before starting the formulation of the elasto-plastic law adopted for the description of the behaviour of the granular soil-structure interfaces subjected to monotonic loading, the following assumptions and definitions are adopted:

1. The interface represents the remoulded zone of soil adjacent to the surface of the structural element. In granular materials, in absence of a direct measurement, the thickness " $\mathrm{t}$ " of this layer can be estimated as being a multiple of the average diameter $\mathrm{D}_{50}$ of the grains with values ranging between 5 to $10 \mathrm{D}_{50}$ for a rough interface ([38] - [40]).

2. The formulation will be limited to the two-dimensional case (case of problems in plane strain or having a symmetry of revolution). Following the general approach of incremental elasto-plasticity the kinematic state variables are the normal relative displacement of the interface, $u_{n}$, and the tangential relative displacement of the interface, $u_{t}$. The associated stress variables are the normal stress, $\sigma_{\mathrm{n}}$, and the shear stress, $\tau$, parallel to the direction of the interface; $\underline{\Sigma}=\left(\sigma_{\mathrm{n}}, \tau\right)^{\mathrm{T}}$ is the stress vector and $\underline{\mathrm{U}}=\left(\mathrm{u}_{\mathrm{n}}, \mathrm{u}_{\mathrm{t}}\right)^{\mathrm{T}}$ is the relative displacement vector.

3. Stresses and relative displacements are taken as positive in compression, and considered homogeneous within the interface layer. The soil is assumed to be dry, so that the analysis can be performed in terms of total as well as effective stresses. 
In the following the general formulation briefly outlined, based on experimental evidence, will be applied to the specific problem of the soil-structure interface.

\section{Elastic response}

The elastic behaviour of the interface is given by the following linear relation:

$$
\underline{\mathrm{d} \Sigma}=\mathbf{K}^{\mathrm{e}} \underline{\mathrm{dU}}^{\mathrm{e}} \quad ; \quad \mathbf{K}^{\mathrm{e}}=\left[\begin{array}{cc}
\mathrm{K}_{\mathrm{n}} & 0 \\
0 & \mathrm{~K}_{\mathrm{t}}
\end{array}\right]
$$

The $\mathbf{K}^{\mathrm{e}}$ is the matrix containing the stiffness of the interface in the normal $\left(\mathrm{K}_{\mathrm{n}}\right)$ and tangential $\left(\mathrm{K}_{\mathrm{t}}\right)$ directions, which might be considered dependent on the initial normal stress and the initial density. For instance, possible expressions are:

$$
\mathrm{K}_{\mathrm{n}}=\mathrm{k}_{\mathrm{n}} \sigma_{\mathrm{ni}}^{\mathrm{N}} ; \mathrm{K}_{\mathrm{t}}=\mathrm{k}_{\mathrm{t}} \sigma_{\mathrm{ni}}^{\mathrm{N}}
$$

where $k_{n}, k_{t}$ and $\mathrm{N}$ are three constitutive parameters of the model, $\sigma_{\mathrm{ni}}$ is the initial normal stress acting on the interface. Note that this choice of the elastic stiffness matrix implies uncoupled behaviour of the interface in the normal and tangential directions.

\section{Stresses: yield criterion and hardening/softening law}

Experimental evidence show that during interface tests under various conditions (i.e. constant normal stress, constant volume, constant normal stiffness) the relationship between normal and shear stresses at failure is well approximated by the Mohr-Coulomb failure criterion. Therefore, neglecting cohesion, the failure condition is given by:

$$
\tau_{\mathrm{f}}=\tan \delta_{\mathrm{f}} \sigma_{\mathrm{n}}=\mu_{\mathrm{f}} \sigma_{\mathrm{n}}
$$

where $\delta_{\mathrm{f}}$ is the friction angle of the interface at failure and $\mu_{\mathrm{f}}=\tan \delta_{\mathrm{f}}$ is the coefficient of friction. In perfect analogy with granular soils, rough interfaces experience during loading (shear) progressive hardening behaviour and significant reduction in shear stiffness until 
failure is reached. Such a hardening phase could either tends to a plateau (loose interfaces) or evolves into strain-softening and then lean towards a final plateau corresponding to the ultimate state (dense interfaces).

A schematic sketch of such a response, in terms of evolution of the stress ratio $\mu=\tau / \sigma_{n}$ and normal displacements $u_{n}$ versus tangential displacements $u_{t}$, is presented in Fig. 1. Continuous hardening, typical of loose interfaces, leads to a progressive mobilisation of the coefficient of friction $\mu$, which increases until reaching the limit value $\mu_{\mathrm{f}}$ at failure. The latter coincides with the ultimate value $\mu_{\mathrm{r}}$ at large tangential displacements (ultimate state). In the case of a loose interface compaction is predominant (see $\mathrm{u}_{\mathrm{n}}{ }^{\mathrm{L}}$ Fig. 1).

The hardening/softening response of the dense interface, on the other hand, corresponds to increasing values of the coefficient of friction $\mu$, which grows towards $\mu_{\mathrm{p}}$, and then decreases to the asymptotic ultimate value $\mu_{\mathrm{r}}$ corresponding to the coefficient of friction at constant volume (ultimate state). In the plane $\sigma_{\mathrm{n}}-\tau$ such an evolution of the stress state during hardening, in agreement with the frictional failure criterion (3), corresponds to a counterclockwise rotation of the locus $\tau=\mu \sigma_{\mathrm{n}}$, starting from the initial position coinciding with the axis $\tau=0$, until the failure line $\left(\mu_{\mathrm{f}}=\mu_{\mathrm{p}}\right)$ defined by equation (3). The softening phase is well represented by a clockwise rotation of the same locus until the ultimate state $\left(\mu_{\mathrm{f}}=\mu_{\mathrm{r}}\right)$. For a loose interface, dilation is preponderant and appears at the beginning of the loading process (see $u_{n}{ }^{D}$ Fig. 1), after a reduced initial phase of compaction.

Consequently the yield mechanisms, whatever hardening or softening, are obtained by a generalisation of the Mohr-Coulomb failure criterion, as suggested by the deviatoric hardening concept ([30] - [33]). The rotation of the yield surface in the $\sigma_{n}-\tau$ stress plane due to deviatoric hardening/softening is assumed to be a function of the plastic tangential relative displacements $\mathrm{u}_{\mathrm{t}}^{\mathrm{p}}$ generated within the interface layer during shearing. 
The yield surface F is governed by the standard Mohr-Coulomb failure criterion; the equation adopted is (see dot line Fig. 2):

$$
\mathrm{F}=\tau-\mu\left(\mathrm{u}_{\mathrm{t}}^{\mathrm{p}}\right) \sigma_{\mathrm{n}}=0
$$

In this equation $\mu\left(\mathrm{u}_{\mathrm{t}}^{\mathrm{p}}\right)$ is the hardening/softening function, giving the evolution of the mobilised friction coefficient during loading.

Based on the schematic diagram shown in Fig. 1, for a loose interface in the hardening regime the function $\mu\left(\mathrm{u}_{\mathrm{t}}^{\mathrm{p}}\right)$ is assumed of hyperbolic type; it can be defined explicitly as:

$$
\mu\left(u_{t}^{p}\right)=\mu_{o}+\left(\mu_{f}-\mu_{o}\right) \frac{u_{t}^{p}}{A\left(\frac{\sigma_{n i}}{p_{o}}\right) t+u_{t}^{p}}
$$

The plastic tangential relative displacement $\mathrm{u}_{\mathrm{t}}^{\mathrm{p}}$ is the hardening parameter of the model.

In equation (5) $\mu_{\mathrm{f}}$ is the coefficient of friction at failure, $\mu_{\mathrm{o}}=\tan \delta_{\mathrm{o}}$ is the friction coefficient delimiting the initial elastic region ( $\delta_{\mathrm{o}}$ is the initial mobilised friction angle). Inside this wedge-shaped region (Fig. 2) only reversible relative displacements are permitted, given by inverting relation (1). The parameter $t$ is the thickness of the interface layer, $\mathrm{A}$ is a parameter of the model governing the shape of the hardening fonction, $\sigma_{\mathrm{ni}}$ is the initial normal stress acting on the interface, and $p_{o}$ is a reference pressure ensuring a dimensionless expression of equation (5). We have assumed $\mathrm{p}_{\mathrm{o}}=1 \mathrm{kPa}$ in all our calculations. The introduction of $\mathrm{t}$ (thickness of the interface layer) into equation (5) allows to consider an internal length parameter for the interface. The ratio $\frac{\sigma_{\mathrm{ni}}}{\mathrm{p}_{\mathrm{o}}}$ is introduced in order to take into account the effect of the initial normal stress $\sigma_{\text {ni }}$ on the shape of the curves of mobilised shear stress. Indeed, as for parameter A, a modification of this ratio via $\sigma_{\mathrm{ni}}$ modifies the shape of the hardening function $\mu\left(u_{t}^{p}\right)$ (eq. (5)). 
As already observed in Fig. 1 in the case of a dense interface, the initial hardening phase with increasing values of $\mu\left(u_{t}^{p}\right)$, after a peak of maximum mobilised friction at failure $\left(\mu_{\mathrm{f}}=\mu_{\mathrm{p}}\right)$, evolves into strain-softening until a final plateau corresponding to the ultimate state $\left(\mu_{\mathrm{f}}=\mu_{\mathrm{r}}\right)$. Thus, in the softening regime it is assumed that the evolution of the yield surface is governed by the following equation:

$$
\mu\left(u_{t}^{p}\right)=\mu_{r}+\left(\mu_{f}-\mu_{r}\right) \operatorname{sech}\left[\frac{A_{o}}{t}\left(u_{t}^{p}-u_{t f}^{p}\right)\right] \text { and } u_{t}^{p}>u_{t f}^{p}
$$

Here three more parameters are introduced, namely: $A_{o}, \mu_{r}$ and $u_{t f}^{p}$. The parameters $A_{o}$ controls the shape of the softening function (6), $\mu_{\mathrm{r}}$ defines the ultimate friction coefficient of the interface at large tangential displacements, i.e. at constant volume or ultimate state. The value $u_{\mathrm{tf}}^{\mathrm{p}}$ is related to the plastic tangential displacement at peak of maximum mobilised friction, and corresponds to the value of the hardening parameter $\mathrm{u}_{\mathrm{t}}^{\mathrm{p}}$ at failure. As a matter of fact the value of $u_{t f}^{p}$ defines the position of the peak of shear resistance. It has to be mentioned that softening behaviour has been considered in this work only with a view of modelling simplicity. There is no doubt that many factors are at the origins of this phenomenon, for instance shear banding instability ([34]) or other various aspects that have been fully described elsewhere and will be not be investigated here ([25], [26], [35]).

\section{Displacements: plastic potential and flow rule}

Plastic relative displacements appear if the condition $\mathrm{F}=0$ and the condition of consistency $\mathrm{dF}=0$ are simultaneously fulfilled. Their magnitude and direction are given by the definition of the plastic potential function $\mathrm{Q}$ and of the flow rule. The pertinent choice of the plastic potential function, $\mathrm{Q}$, is essential to reproduce the typical volumetric behaviour observed 
during interface tests (Fig. 1). Consequently, its expression should be suitable for the description of the following phenomena:

1) the presence of an initial compaction $\left(d_{n}>0\right)$ in a test with constant normal stress, or correspondingly a reduction of the stress $\sigma_{\mathrm{n}}$, normal to the interface layer, in a test with imposed constant volume or constant normal stiffness;

2) the existence of a threshold corresponding to the phase transformation from compaction $\left(\mathrm{du}_{\mathrm{n}}>0\right)$ to dilatancy $\left(\mathrm{du}_{\mathrm{n}}<0\right)$, which corresponds, in a test with imposed constant volume or constant stiffness, to an increase of the normal stress $\sigma_{\mathrm{n}}$;

3) the stabilisation of the normal relative displacement $u_{n}$, or the normal stress $\sigma_{n}$, on an asymptotic value for large relative tangential displacements of the interface (i.e. $\mathrm{du}_{\mathrm{n}}=0$ or $\mathrm{d} \sigma_{\mathrm{n}}=0$ ). This corresponds to the salient features of the critical state theory, where constant volume conditions are assumed at failure.

Compaction (i.e. $\mathrm{du}_{\mathrm{n}}>0$ or $\mathrm{d} \sigma_{\mathrm{n}}<0$ ) due to grain crushing at very large tangential displacements and/or high normal stresses is not considered in the present version of the model.

In order to describe the above-mentioned phenomena (points (1) to (3)), non-associated elasto-plasticity has been assumed. The plastic potential function is:

$$
\mathrm{Q}=\tau+\mu_{\mathrm{c}} \sigma_{\mathrm{n}} \ln \left(\frac{\sigma_{\mathrm{n}}}{\sigma_{\mathrm{o}}}\right)
$$

where the parameter $\mu_{\mathrm{c}}$ is the slope of the phase transformation line $\tau=\mu_{\mathrm{c}} \sigma_{\mathrm{n}}$ and $\sigma_{\mathrm{o}}$ is defined by the current state of stress acting on the interface. Taking into account equation (7), $\sigma_{0}$ can be expressed as:

$$
\sigma_{o}=\sigma_{n} \exp \left(\frac{\mu}{\mu_{c}}\right)
$$


The plastic potential function introduced is analogous to the original formulation proposed by Schofield and Wroth [41] in the Cam Clay model. In this respect, it is worth mentioning that Nova [42] first introduced in an elasto-plastic theoretical framework the modelling of the phase transformation state in soils, using the same form of the plastic potential. Typical plots of the function Q in the $\sigma_{\mathrm{n}}-\tau$ plane are presented in Fig. 2. This function describes a series of continuous surfaces which expand progressively during deformation, changing in size but not in shape (i.e. with the same derivatives on points having the same coefficient of mobilised friction). Differentiating equation (7) and rearranging using equation (8), the plastic increments of relative displacement are:

$$
\left[\begin{array}{l}
d u_{n}^{p} \\
d u_{t}^{p}
\end{array}\right]=d \lambda\left[\begin{array}{c}
\mu_{c}-\mu \\
1
\end{array}\right]
$$

Thus compaction holds if $\mu<\mu_{\mathrm{c}}\left(\mathrm{du}_{\mathrm{n}}^{\mathrm{p}}>0\right)$ and dilatancy takes place if $\mu>\mu_{\mathrm{c}}\left(\mathrm{du}_{\mathrm{n}}^{\mathrm{p}}<0\right)$. The phase transformation state corresponds to the condition $\mu=\mu_{c}$, as a result $\mathrm{du}_{\mathrm{n}}^{\mathrm{p}}=0$ (points $\mathrm{A}$, $\mathrm{B}, \mathrm{C}$ in Fig. 2). The dilatancy of the interface, $\mathrm{D}$, is given by the following relation:

$$
\mathrm{D}=\frac{\mathrm{du}_{\mathrm{n}}^{\mathrm{p}}}{\mathrm{du}_{\mathrm{t}}^{\mathrm{p}}}=\mu_{\mathrm{c}}-\mu
$$

It is worth noting that dilatancy at large relative tangential displacements is constant and tends towards the asymptotic value $\mathrm{D}=\mu_{\mathrm{c}}-\mu_{\mathrm{r}}\left(\mu_{\mathrm{r}}=\mu_{\mathrm{f}}\right.$ in a loose interface). Therefore, ultimate zero rate of volumetric deformation of the interface at large tangential displacements, in agreement with experimental observations (i.e. ultimate state), cannot be reproduced if equation (7) is considered.

In order to introduce this further important feature of the volumetric behaviour of the interface, a modified form of the potential function is now proposed. 


\section{Behaviour at ultimate state}

We examine now the conditions that allow to introduce the required zero dilatancy rate at the interface associated to the ultimate state. From equation (10) such a requirement is fulfilled if

$$
\mathrm{u}_{\mathrm{t}} \rightarrow \infty \Rightarrow \mathrm{D}=\left(\mu_{\mathrm{c}}-\mu\right) \rightarrow 0
$$

In addition, at ultimate state, we also know that:

$$
\mathrm{u}_{\mathrm{t}} \rightarrow \infty \Rightarrow \mu \rightarrow \mu_{\mathrm{r}}=\tan \delta_{\mathrm{r}}=\text { constant }
$$

and $\mu_{\mathrm{r}}=\mu_{\mathrm{f}}$ in the case of continuous hardening until ultimate state condition. From equations (11) and (12) it can be deduced that:

$$
\mathrm{u}_{\mathrm{t}} \rightarrow \infty \Rightarrow \mathrm{D}=\left(\mu_{\mathrm{c}}-\mu_{\mathrm{r}}\right) \rightarrow 0
$$

and condition (13) is fulfilled if

$$
\mu_{\mathrm{c}} \rightarrow \mu_{\mathrm{r}}
$$

Consequently, the condition of zero dilatancy at the interface at ultimate state can be obtained if the coefficient $\mu_{\mathrm{c}}$, the stress ratio at phase transformation state, increases after phase transformation towards the final value $\mu_{\mathrm{r}}$ (i.e. towards the stress ratio at ultimate state). Condition (14) corresponds to an evolution of the size of both compaction and dilation regions in Fig. 2. The mechanism is described in Fig. 3, on a typical stress path involving initial compaction, phase transformation and dilatancy (e.g. interface tests at constant volume), without taking into account for the time being softening behaviour (towards $\mu_{\mathrm{f}}=\mu_{\mathrm{r}}$ ). Following the indicated path, at point $\mathrm{C}$, for a friction coefficient $\mu=\mu_{\mathrm{co}}$ there is a transition from compaction $\left(\mu<\mu_{\mathrm{co}}\right)$ to dilatancy $\left(\mu>\mu_{\mathrm{co}}\right)$. At a generic point $\mathrm{M}$, in the dilation region, two different potential surfaces are plotted. The first $\left(\mathrm{Q}^{\prime}{ }_{\mathrm{o}}\right)$ is given by the family of functions in equation (7), admitting $\mu_{\mathrm{co}}$ constant. The second $\left(\mathrm{Q}_{1}\right)$ has been plotted admitting an increase of the coefficient $\mu_{\mathrm{c}}$ from the initial value $\mu_{\mathrm{co}}$ to $\mu_{\mathrm{c} 1}$ according to condition (14). By 
comparing the direction of the plastic displacement vector at point $\mathrm{M}$, it can be argued that dilatancy at the interface can be substantially reduced assuming $\mathrm{Q}_{1}$ as the current potential function. The minimum value of dilatancy is obtained when the phase transformation surface $\tau=\mu_{\mathrm{c} 1} \sigma_{\mathrm{n}}$ is close to the failure locus $\tau=\mu_{\mathrm{f}} \sigma_{\mathrm{n}}$, so that $\mathrm{D}=\left(\mu_{\mathrm{c} 1}-\mu_{\mathrm{f}}\right) \rightarrow 0$ (condition (13) with $\left.\mu_{\mathrm{r}}=\mu_{\mathrm{f}}\right)$. This is associated to a progressive shrinkage of the dilation region. If softening is expected $\left(\mu_{\mathrm{f}}=\mu_{\mathrm{p}}\right)$, after reaching the maximum value $\mu_{\mathrm{p}}$, the coefficient of friction reduces to $\mu_{\mathrm{r}}$ while the dilation region slightly expands (Fig. 2). In this case the minimum value of dilatancy is obtained when the phase transformation surface is close to the ultimate locus $\tau=\mu_{\mathrm{r}} \sigma_{\mathrm{n}}$, so that $\mathrm{D}=\left(\mu_{\mathrm{c} 1}-\mu_{\mathrm{r}}\right) \rightarrow 0$. Such a mechanism has a direct physical interpretation. Yield of dense interface layers due to shearing causes plastic dilation, resulting in an increase of the voids in the sample (shrinkage of the dilation region). On the other hand, shearing on loose interface layers causes an opposite effect, leading to an overall compaction of the interface and a reduction of the void ratio (shrinkage of the compaction region).

It is noticed that, within the theoretical framework of the model, this is equivalent to a change in shape of the surfaces given by the plastic potential function Q (equation (7)), which is implicitly taken into account by allowing for an evolution of parameter $\mu_{\mathrm{c}}$. It is then admitted that the parameter $\mu_{\mathrm{c}}$ in equation (7) is not a constant during deformation but is a function of plastic tangential displacement $\mathrm{u}_{\mathrm{t}}^{\mathrm{p}}$ (hardening parameter), so that:

$$
\mu_{\mathrm{c}}=\mu_{\mathrm{c}}\left(\mathrm{u}_{\mathrm{t}}^{\mathrm{p}}\right)
$$

After that, the equation of plastic potential function can not be a function of the plastic displacement. However, in the specific case where the form of the yield surface is always linear (equation (4)) with the hardening/softening functions as in equations (5) and (6), the direction of plastic flow at any point of the stress space remains path-independent. 
In order to reproduce the condition of shearing at constant volume at large tangential displacements (i.e. ultimate state), the following expression is proposed for the parameter $\mu_{\mathrm{c}}=\mu_{\mathrm{c}}\left(\mathrm{u}_{\mathrm{t}}^{\mathrm{p}}\right)$ :

$$
\mu_{\mathrm{c}}\left(\mathrm{u}_{\mathrm{t}}^{\mathrm{p}}\right)=\mu_{\mathrm{co}}+\left(\mu-\mu_{\mathrm{co}}\right) \mathcal{D}\left(\mathrm{u}_{\mathrm{t}}^{\mathrm{p}}\right)
$$

The rate of dilatancy at the interface is controlled by the function $\mathcal{D}\left(\mathrm{u}_{\mathrm{t}}^{\mathrm{p}}\right)$, defined as

$$
\mathscr{D}\left(\mathrm{u}_{\mathrm{t}}^{\mathrm{p}}\right)=1-\operatorname{sech}\left[\frac{\mathrm{B}}{\mathrm{t}}\left(\frac{\sigma_{\mathrm{ni}}}{\mathrm{p}_{\mathrm{o}}}\right) \mathrm{u}_{\mathrm{t}}^{\mathrm{p}}\right]
$$

In equations (16) and (17), B is a constitutive parameter of the model, $\mu$ is the coefficient of friction mobilised during shearing, $\sigma_{\mathrm{ni}}$ is the initial normal stress, $\mathrm{t}$ is the thickness of the interface and $\mathrm{p}_{\mathrm{o}}$ is the reference pressure. Again, the ratio $\frac{\sigma_{\mathrm{ni}}}{\mathrm{p}_{\mathrm{o}}}$ is introduced in order to take into account the observed reduction in dilatancy at higher normal stresses. Obviously, at phase transformation $\mu=\mu_{c o}$, and equation (16) is thus written $\mu_{\mathrm{c}}\left(\mathrm{u}_{\mathrm{t}}^{\mathrm{p}}\right)=\mu_{\mathrm{co}}$. Figure 4 shows the evolution of $\mu, \mu_{c}$ and dilatancy $\mathrm{D}=\mu_{\mathrm{c}}-\mu$ versus the hardening parameter $\mathrm{u}_{\mathrm{t}}^{\mathrm{p}}$ (plastic tangential displacement).

In the case of a dense interface dilation is predominant (see $u_{n}{ }^{D}$ in Fig. 4). The coefficient of friction $\mu$ first increases towards $\mu_{\mathrm{p}}$ and then decreases towards $\mu_{\mathrm{r}}$ (equations (5) and (6), hardening/softening response), while $\mathcal{D}(\mathrm{e})$ increases towards unity (equation (17)). Therefore equation (16) at ultimate state can be written:

$$
\mu_{\mathrm{c}}\left(\mathrm{u}_{\mathrm{t}}^{\mathrm{p}}\right)=\mu
$$

and on the basis of equation (11) $\mathrm{D}=0$.

In the case of a loose interface, compaction appears from the beginning of the loading process (see $u_{n}{ }^{L}$ in Fig. 4). The coefficient of friction $\mu$ increases progressively until the limit value $\mu_{\mathrm{r}}$ 
(equation (5)) and, as in the case of a dense interface, $\mathcal{D}\left(\mathrm{u}_{\mathrm{t}}^{\mathrm{p}}\right)$ increases towards the unity (equation (17)). Again, based on a similar discussion, condition (18) is fulfilled at large tangential displacements and $\mathrm{D}=0$. It must be noted that for a loose interface the value of $\mu_{\mathrm{co}}^{\mathrm{L}}$

(Fig. 4) is close to the limit value $\mu_{\mathrm{r}}$. This leads to a reduced rate of mobilised dilatancy during shear and an overall compressive volumetric behaviour of the interface.

\section{Identification of constitutive parameters of the model}

As formulated the model requires fourteen parameters; these are: $k_{n}, k_{t}, N, \mu_{o}, \mu_{p}, u_{t f}^{p}, \mu_{r}$, $\mu_{\mathrm{co}}, \mathrm{A}, \mathrm{A}_{\mathrm{o}}, \mathrm{B}, \sigma_{\mathrm{ni}}, \mathrm{t}$ and $\mathrm{p}_{\mathrm{o}}$. Eleven among the fourteen parameters mentioned need to be determined with a specific procedure. Indeed, the value of $\sigma_{\mathrm{ni}}$ is given by the initial condition of the test (in terms of initial normal stress acting on the interface), the value of $t$ (thickness of the interface layer) is assumed proportional to the value of the $\mathrm{D}_{50}$ of the granular medium and $\mathrm{p}_{\mathrm{o}}$ is a reference pressure (assumed equal to $1 \mathrm{kPa}$ in this work).

For the determination of the remaining eleven constitutive parameters one can use results of interface tests at constant normal stress or constant volume and, if available, the results of oedometric or isotropic compression tests. In the following, the methodology of parameters determination is briefly examined.

\section{Elastic parameters: $\boldsymbol{k}_{n}, \boldsymbol{k}_{t}$ and $\mathrm{N}$}

On the basis of relation (1), the normal and tangential stiffness of the interface depend on the values of parameters $k_{n}, k_{t}$ and $N$. These relations are similar to existing empirical relationships proposed for the Young's modulus of granular materials. Both $k_{n}$ and $k_{t}$ are introduced in order to take into account the dependence of the stiffness on density, whereas the coefficient $\mathrm{N}$ allows to consider a possible dependence on the normal stress. If $\mathrm{N}=0$, the dependence on the normal stress is neglected, in this case $\mathrm{k}_{\mathrm{n}}$ and $\mathrm{k}_{\mathrm{t}}$ are directly the normal and 
tangential stiffness of the interface, respectively.

The value of parameter $\mathrm{N}$ is obtained through curve fitting of the values of the initial tangential stiffness plotted against the applied initial normal stresses $\sigma_{\mathrm{ni}}$. As it will be discussed later in this section, due to the difficulty in the estimation of $K_{n}$, we have considered for $\mathrm{N}$ the usual value 0.55 obtained for the Young's modulus of silica sands (Fontainebleau sand) from triaxial tests on samples at various density ([36]).

The parameter $\mathrm{k}_{\mathrm{t}}$ is found knowing the initial slope of the curve of mobilised shear stress $(\tau)$ versus tangential displacement $\left(\mathrm{u}_{\mathrm{t}}\right)$ of the interface. Such a slope, corresponding to the ratio $\frac{\tau}{u_{t}}$, is the value of the tangential stiffness $K_{t}$. The determination of the initial slope is rather delicate and often imprecise. In practice, one can either consider a secant stiffness or, if available, the slope of the unloading branch of the shear stress versus tangential displacement curve. For instance, in the first case it can be assumed that:

$$
\mathrm{K}_{\mathrm{t}}=\frac{\tau_{\mathrm{f}}}{\mathrm{u}_{\mathrm{to}}}
$$

where $u_{t o}$ is the tangential displacement when $\tau=\frac{\tau_{f}}{2}, \tau_{f}$ is the maximum shear strength and $\sigma_{\mathrm{ni}}$ is the value of the initial normal stress acting on the interface. From equation (1) it can be deduced that:

$$
\mathrm{k}_{\mathrm{t}}=\frac{\mathrm{K}_{\mathrm{t}}}{\sigma_{\mathrm{ni}}^{\mathrm{N}}}
$$

The parameter $\mathrm{k}_{\mathrm{n}}$ depends on the compressibility of the interface. Its determination is thus possible from oedometric compression tests on the interface material. Obviously, this type of test is not easy to perform, because of the difficulty to reconstitute samples having small thickness at a given initial density. Moreover this determination is systematically biased by 
the effect of the remaining part of the undisturbed (not sheared) soil sample. Other factors, such as the density state, the normal stress level, the type of test (constant normal stress, constant volume) and the type of apparatus also affect the determination of interface normal stiffness. When appropriate, it is proposed to deduce $\mathrm{k}_{\mathrm{n}}$ from standard eodometric compression tests. Volume changes during oedometric compression are:

$$
\frac{\mathrm{dv}}{\mathrm{v}_{\mathrm{i}}}=\frac{\mathrm{de}}{1+\mathrm{e}_{\mathrm{i}}}=\frac{\mathrm{dh}}{\mathrm{h}_{\mathrm{i}}}
$$

where $v_{i}$ is initial specific volume, $h_{i}$ is the initial height of the sample and $e_{i}$ is the initial void ratio. In oedometric compression:

$$
\mathrm{dv}=-\mathrm{C}_{\mathrm{s}}^{\prime} \frac{\mathrm{d} \sigma_{\mathrm{v}}}{\sigma_{\mathrm{v}}}
$$

where $\mathrm{C}_{\mathrm{s}}$, is the swelling index giving the slope of the unloading branch of the vertical (normal) stress $\left(\sigma_{\mathrm{v}}\right)$ versus the specific volume change curve. Then, from equations (21) and (22):

$$
\mathrm{d} \sigma_{\mathrm{v}}=-\frac{\sigma_{\mathrm{v}}\left(1+\mathrm{e}_{\mathrm{i}}\right)}{\mathrm{C}_{\mathrm{s}}^{\prime} \mathrm{h}_{\mathrm{i}}} \mathrm{dh}
$$

Equation (23) allows to identify the normal stiffness of the interface, admitting that during the direct shear test the behaviour of the interface in the normal direction is of "oedometric type" with same elastic soil properties. We obtain:

$$
\mathrm{K}_{\mathrm{n}}=\frac{\sigma_{\mathrm{ni}}\left(1+\mathrm{e}_{\mathrm{i}}\right)}{\mathrm{C}_{\mathrm{s}}^{\prime} \mathrm{t}}
$$

where $\sigma_{\mathrm{ni}}$ is the normal stress acting on the interface and $\mathrm{t}$ is the thickness of the interface. It is then possible to evaluate $\mathrm{k}_{\mathrm{n}}$

$$
\mathrm{k}_{\mathrm{n}}=\frac{\mathrm{K}_{\mathrm{n}}}{\sigma_{\mathrm{ni}}^{\mathrm{N}}}
$$




\section{Plastic parameters: $\mu_{o}, \mu_{p}, u_{t f}^{p}, \mu_{r}$ and $\mu_{c o}$}

The value of the parameter $\mu_{\mathrm{o}}=\tan \delta_{\mathrm{o}}$ defines the extension of the initial elastic region of the interface, where $\delta_{\mathrm{o}}$ is the minimum friction angle mobilised at the interface (Fig. 2).

The parameters $\mu_{\mathrm{f}}$ and $\mu_{\mathrm{r}}$ are the coefficients of friction of the interface at peak and at ultimate state, respectively. Usually $\mu_{\mathrm{f}}=\mu_{\mathrm{r}}$ in loose interfaces and $\mu_{\mathrm{f}}=\mu_{\mathrm{p}}>\mu_{\mathrm{r}}$ in dense interfaces. They can be determined easily from interface tests at different constant normal stresses by linear interpolation of points $\left(\sigma_{\mathrm{n}}, \tau\right)$ at peak failure and at ultimate state. Their values correspond to the slope of the Mohr-Coulomb peak failure line $\left(\mu_{\mathrm{f}}\right)$ and the ultimate linear envelope at ultimate state $\left(\mu_{\mathrm{r}}\right)$, as shown in Fig. 2. It should be mentioned that, due to the amplification of dilation characteristics of granular materials at low imposed normal stress levels, such a determination could lead to a small underestimation of $\mu_{\mathrm{f}}$.

As mentioned, the value of $\mathrm{u}_{\mathrm{tf}}^{\mathrm{p}}$ defines the position of peak shear resistance in the diagram $\mathrm{u}_{\mathrm{t}}-\tau$ (Fig. 1) and is adjusted in order to have the best curve fitting. We emphasise that here the aim is not to give a criterion to detect the instability point corresponding to the peak shear resistance. For a first estimation of $u_{\mathrm{tf}}^{\mathrm{p}}$ it is proposed to apply the additivity postulate, we can write

$$
\mathrm{u}_{\mathrm{tf}}^{\mathrm{p}}=\mathrm{u}_{\mathrm{tf}}-\mathrm{u}_{\mathrm{tf}}^{\mathrm{e}}
$$

Here $\mathrm{u}_{\mathrm{tf}}^{\mathrm{e}}$ is the elastic tangential relative displacement given by

$$
\mathrm{u}_{\mathrm{tf}}^{\mathrm{e}}=\frac{\tau_{\mathrm{f}}}{\mathrm{K}_{\mathrm{t}}}
$$

$\tau_{\mathrm{f}}$ and $\mathrm{u}_{\mathrm{tf}}$ are the shear stress and the tangential relative displacement at the peak of shear resistance, respectively (Fig. 1). Obviously, if no peak is present in the $u_{t}-\tau$ curve (case of a loose interface, Fig. 1), $\mathrm{u}_{\mathrm{tf}}^{\mathrm{p}}$ value is assumed large enough to avoid the occurrence of the 
peak.

The parameter $\mu_{\mathrm{co}}$ is the coefficient of friction at the points of phase transformation (Fig. 2). At these points, the rate of the normal relative displacement or the variation of the normal stress are zero (Figs. 3 and 4). The value of $\mu_{\mathrm{co}}$ can be identified much easier from an interface test at constant volume: it can be determined at the point of inversion of the stress path in $\sigma_{\mathrm{n}}-\tau$ plane (point $\mathrm{C}$ in Fig. 3).

\section{Parameters: $A, A_{o}$ and $B$}

The parameter A appears in the expression of the hyperbolic hardening function (5). It allows for the control of the shape of the curve of mobilised friction at the interface. Differentiating equation (4), it is possible to write:

$$
\frac{\mathrm{d} \tau}{d u_{\mathrm{t}}^{\mathrm{p}}}=\frac{\sigma_{\mathrm{ni}}\left(\mu_{\mathrm{f}}-\mu_{\mathrm{o}}\right) \beta}{\left(\beta+\mathrm{u}_{\mathrm{t}}^{\mathrm{p}}\right)^{2}} \quad ; \quad \beta=\mathrm{A} \frac{\sigma_{\mathrm{ni}}}{\mathrm{p}_{\mathrm{o}}} \mathrm{t}
$$

Where $t$ is the thickness of the interface layer, assumed to be a multiple of the average grain diameter $\mathrm{D}_{50}$. The value of $\mathrm{A}$ can be obtained imposing the continuity of the value of the initial slope of the experimental curve $\left(u_{t}, \tau\right)$ with the value of the analytical tangent $\frac{d \tau}{d u_{t}^{p}}$ given in equation (28), calculated when $u_{t}^{p}=0$. The initial slope of the experimental curve $\left(u_{t}, \tau\right)$ is the tangential stiffness $K_{t}$, so that

$$
\frac{\sigma_{\mathrm{ni}}\left(\mu_{\mathrm{f}}-\mu_{\mathrm{o}}\right)}{\beta}=\mathrm{K}_{\mathrm{t}}
$$

As a result, the parameter $\mathrm{A}$ is 


$$
A=\frac{\left(\mu_{f}-\mu_{o}\right) p_{o}}{K_{t} t}
$$

The parameters $\mathrm{A}_{\mathrm{o}}$ and $\mathrm{B}$ can be deduced following a procedure of optimisation by successive adjustments. $A_{o}$ controls the shape of the softening function in equation (6), B controls directly the shape of the evolution rule of the parameter $\mu_{\mathrm{c}}$ (equation (17)) and indirectly the rate of mobilisation of dilatancy at the interface (equation (10)).

\section{Comparison between model predictions and experimental results}

The validation of the proposed approach for interface modelling has been performed considering three classes of tests on the interface: tests at constant normal stress, tests at constant volume and tests at constant normal stiffness. We present in the following the results of the comparison between model predictions and experimental results.

\section{Test at constant normal stress}

Two different sets of experimental results of direct shear tests on the interface have been considered in order to validate the model on a constant normal stress path.

The first set of experimental data ([36]) has been obtained performing interface tests in a modified direct shear box between a loose Fontainebleau sand and a rough metal plate $\left(R_{n}=1\right.$ as defined in [10]). The physical characteristics of this sand are summarised in Table 1. Loose sand samples have been reconstituted pouring dry sand inside a square shear box $60 \mathrm{~mm} \times 60$ $\mathrm{mm}$. Density states are controlled by two parameters: the rate of deposition and the height of grains drop. One advantage of dry pluviation is that the repeatability of the process is satisfactory. Following this procedure initial density index $\mathrm{I}_{\mathrm{D}}$ equal to $0.46\left(\mathrm{e}_{\mathrm{o}}=0.753\right)$ have been obtained. An imposed normal stress ranging between $25 \mathrm{kPa}$ and $100 \mathrm{kPa}$ has been 
applied before shearing. These tests show clearly the influence of the normal stress level on the behaviour of the interface, involving: higher values of maximum shear stress (Fig. 6a) and decreasing at the interface when $\sigma_{\text {ni }}$ increases (Fig. 6b)

The second set of experimental data examined are taken from the two interface tests presented by Tabucanon and Airey [6]. The tests were performed in a modified direct shear box on samples of siliceous Sidney sand and rough interface. This sand has physical characteristics similar to Fontainebleau sand (Table 1). Details of the experimental procedure can be found in the original reference. Both tests were carried out at constant normal stress $\sigma_{\mathrm{n}}=150 \mathrm{kPa}$; the authors considered two different densities, namely $I_{D}=0.15\left(e_{o}=0.790\right.$, test $\left.A\right)$ and $I_{D}=0.96$ $\left(e_{\mathrm{o}}=0.580\right.$, test $\left.\mathrm{B}\right)$. As a consequence these tests allow to assess the influence of the material density on the mechanical response of the interface, as well as the capability of the model in reproducing it.

Numerical computations of the interface tests on Fontainebleau sand have been performed with the set of parameters determined from test SB3 at $\sigma_{\mathrm{n}}=100 \mathrm{kPa}$ (Table 2). Other tests have been simulated just changing the initial conditions in terms of imposed normal stress $\sigma_{\mathrm{ni}}$. The results of the simulations are also presented in Fig. 6. The comparison between the experimental results and simulations is satisfactory with regard to the evolution of the shear stress $(\tau)$ and the normal displacement $\left(u_{n}\right)$ versus the tangential displacement of the interface $\left(\mathrm{u}_{\mathrm{t}}\right)$. As it can be noted, there is a slight underestimation of the maximum peak shear stress predicted by the model for the tests carried out at low levels of normal stress. As evoked, this divergence between simulations and the experiments translates the effect of $\sigma_{\mathrm{n}}$ on the value of $\mu_{\mathrm{p}}$ (i.e. non-linearity of Mohr-Coulomb failure line in the $\sigma_{\mathrm{n}}-\tau$ plane for low values of $\sigma_{\mathrm{n}}$ ). With regard to the evolution of the normal relative displacement $\left(\mathrm{u}_{\mathrm{n}}\right)$ versus the tangential relative displacement $\left(\mathrm{u}_{\mathrm{t}}\right)$, it can be observed that the transition from compaction to dilatancy reproduced by the model is more gradual than the observed experimental response. It should 
be mentioned, however, that the shapes of the experimental curves are rather singular. Indeed, where dilatancy appears (i.e. at low normal stress levels), the experimental results also show an extended initial phase where the change of normal relative displacement is zero (test SB1 with $\sigma_{\mathrm{n}}=25 \mathrm{kPa}$ ), or a very prolonged phase where the rate of normal relative displacement is zero (test $\mathrm{SB} 2$ with $\sigma_{\mathrm{n}}=50 \mathrm{kPa}$ ).

It is emphasised that the transition from compaction (test SB3, Fig. 6b) to dilatancy (test SB1) is associated exclusively to the change in normal stress $\sigma_{\mathrm{n}}$. This behaviour is well depicted by

the model via the ratio $\frac{\sigma_{n i}}{p_{o}}$ introduced in equation (17) in order to control the rate of dilatancy, which increases when $\sigma_{\mathrm{ni}}$ decreases.

For the simulations of interface test on Sidney sand, the complete set of parameters used has been obtained from the experimental results of test A (Table 2). For such computations, due to the lack of experimental data, we have assumed $\mathrm{k}_{\mathrm{n}}=2 \mathrm{k}_{\mathrm{t}}$. The comparison between the experimental results and simulations is presented in Fig. 7. The predictions are again satisfactory; as it is possible to observe, the softening phase present in test B is well captured by the numerical computations, as well as the response in terms of volumetric deformations due to the transition from a loose state to a dense state.

\section{Test at constant volume}

In order to check the model predictions on different stress path conditions, the results of interface tests at constant volume between Fontainebleau sand and rough metal plate $\left(R_{n}=1\right)$ are now analysed. These tests have been carried out on a ring simple shear apparatus ([12], [13]). A detailed description of this apparatus, showing its advantages and its shortcomings can be found in the given references and is discussed by De Gennaro [36]. In the ring simple shear apparatus the shear stress is applied to the internal surface of a thin-walled cylinder of granular material (Fontainebleau sand in this study) via a cylindrical inclusion subjected to 
torsion. Rigid steel platens at the top and the bottom of the soil sample allow to reproduce plane strains conditions, and a glass window, integrated into the bottom steel platen, allows for the visualisation of grain motion at the interface ([37]). Therefore for these tests it has been possible to estimate by direct visualisation the thickness of the interface layer, assumed equal to $10 \mathrm{D}_{50}(2 \mathrm{~mm})$. The dimension of the annular sample are: $100 \mathrm{~mm}$ in height, $100 \mathrm{~mm}$ of inner radius, $200 \mathrm{~mm}$ of external radius. The sample is contained into a latex membrane and confined externally using a pressure-volume controller (GDS); the constant volume condition is obtained by a servo-mechanism allowing the control of the pressure of water injected or ejected as a function of the volume target (initial volume of the sample). Obviously this is a "global" constant volume condition, obtained all over the sample, and not restricted at the interface layer. Three test results ([36]) corresponding to initial external radial pressure of $100 \mathrm{kPa}$ (test CS1), $200 \mathrm{kPa}$ (test CS2) and $400 \mathrm{kPa}$ (test CS3) are simulated. The sand samples tested have an initial density index $\mathrm{I}_{\mathrm{D}}$ of about $0.49\left(\mathrm{e}_{\mathrm{o}}=0.743\right)$, and the normalised roughness of the surface of the cylinder is $R_{n}=1$.

The numerical computations have been performed assuming the set of parameters given in Table 3, determined from the results of test CS1 at $\sigma_{\mathrm{n}}=100 \mathrm{kPa}$. The definition of this new set of parameters has been necessary although the same sand (Fontainebleau sand) has been used for both tests carried out with the ring simple shear apparatus and the modified direct shear box (Table 2). This is due to the dependency of the mechanical characteristics of the interface on the different boundary conditions imposed by the two testing devices.

It can be seen that the computed responses match quite well the observed experimental results (Fig. 7), although the computed restrained contractancy predicted by the model (local reduction of $\sigma_{\mathrm{n}}$ ) for the higher levels of normal (radial) stress acting on the interface seems to be overestimated.

As a concluding remark, it should be mentioned that the difference between the thickness of 
the sand samples $(100 \mathrm{~mm})$ and the average grain size of the sand $(0.2 \mathrm{~mm})$ being quite large, the state of stress inside the sample can not be assumed to be rigorously homogeneous. As a consequence the mechanical response of the sample in terms of evolution of the external radial pressure should be considered in a qualitative way. As a matter of fact, it does not correspond to the real (local) behaviour of the interface in the normal (radial) direction. From a computational viewpoint it is believed that this is not of major trouble, in the sense that the right trends of the mechanical behaviour of the interface should be well captured by the model, which is the case.

\section{Test at constant normal stiffness}

The final set of interface tests considered in order to validate the capability of the model is the one presented recently by Fakharian and Evgin [43]. Tests were conducted on a Cyclic 3Dimensional Simple Shear Interface (C3DSSI) apparatus between samples of medium Silica sand and steel plates having variable range of roughness. The only relevant physical characteristic reported by the authors is a $\mathrm{D}_{50}$ of $0.6 \mathrm{~mm}$ (Table 1). Also in this case details of the experimental procedure can be found in the original reference. We have considered three tests carried out between dense Silica sand $\left(I_{D}=0.88\right)$ and rough steel plate. One test has been performed at constant normal stress $\sigma_{\mathrm{n}}=100 \mathrm{kPa}$ (Test 1, Fig. 9). The other two tests (Test 2 and Test 3) were conducted with the same initial conditions given in test Test $1\left(\sigma_{\mathrm{n}}=100\right.$ $\mathrm{kPa}, \mathrm{I}_{\mathrm{D}}=0.88$ ), but imposing during the test a constant normal stiffness as a new boundary condition (i. e. $d \sigma_{\mathrm{n}} / \mathrm{du}_{\mathrm{n}}=\mathrm{K}$ ). The calibration of model parameters have been achieved using the results of the constant normal stress test Test 1 at $\sigma_{\mathrm{n}}=100 \mathrm{kPa}$ (Table 2 ), the values of the stiffness $K_{n}$ and $K_{t}$ which are those proposed by Fakharian and Evgin [43]. These parameters were consequently used to predict the results of tests Test 2 and Test 3 at constant normal stiffness of $400 \mathrm{kPa} / \mathrm{m}$ and $800 \mathrm{kPa} / \mathrm{m}$, respectively. The results of the simulations presented 
in Fig. 9 seem to be qualitatively and quantitatively in agreement with the experimental results. This agreement is obviously good for the Test 1 , which served for the parameter calibration.

\section{Closure}

This work addresses the description of the mechanical behaviour of granular soil-structure interfaces. To this purpose, the formulation of an elasto-plastic model able to describe the main features of the behaviour of the interface is proposed. The model allows for the description of the basic aspects identified in the interface tests, such as: hardening/softening mechanical response, phase transformation and ultimate state. It also includes the effect of the normal stress level on the mobilised dilatancy at the interface.

It is believed that the major advantages of the proposed constitutive law lie in the fact that:

1) parameters have a direct meaning and are relatively easy to found;

2) behaviour at ultimate state is introduced in a simple way, and reflect the relevant physical mechanisms involved (compaction and dilation).

With respect to point (1), the number of parameters of the model is somewhat limited and a methodology for their determination has been briefly outlined. Concerning point (2), as already discussed in section 2 , the mechanism associated to the modelling of the interface behaviour at ultimate state is fully consistent with the choice of the plastic potential function and its evolution.

The validation of the proposed approach has been carried out on the experimental results of interface tests achieved by means of a modified direct shear box, a ring simple shear apparatus and a Cyclic 3-Dimensional Simple Shear apparatus (C3DSSI). However, other stress paths or boundary conditions could be considered in future works. The model provides satisfactory predictions of the behaviour of the interface for tests at imposed constant normal 
stress, at imposed constant global volume and finally at imposed constant normal stiffness. It is believed that further improvements of the present version could be included in the formulation of the constitutive law without major difficulties, namely: cyclic loading and material degradation (grain crushing).

\section{Acknowledgements}

The authors would like to express grateful appreciation for the support offered by the

European Commission Programme "ALERT Geomaterials". The precious collaboration of

Dr. G. Bosco and Dr. A. Tarantino (University of Trento, Italy) is also acknowledged.

\section{References}

[1] Potyondy JG. Skin friction between various soils and construction materials. Géotechnique 1961; 11 (4): 339-353.

[2] Wernick E. Skin friction of cylindrical anchors in non-cohesive soils. Symposium on Soil Reinforcing and Stabilising Techniques, Sydney 1978: 201-219.

[3] Desai CS, Drumm CE, Zaman MM. Cyclic testing and modelling of interfaces. J. Geotech. Engrg. Div. ASCE 1985, 111 (GT6): 793-815.

[4] Boulon M. Contribution à la mécanique des interfaces sol-structures. Application au frottement latéral des pieux. Mémoire pour l'habilitation à diriger des recherches, Université Joseph Fourier - Grenoble I, Grenoble, 1988.

[5] Hoteit N. Contribution à l'étude du comportement d'interface sable-inclusion et application au frottement apparent. Thèse de Doctorat de l'Institut National Polytechnique de Grenoble, Grenoble, 1990.

[6] Tabucanon JT, Airey DW. Interface tests to investigate pile skin friction in sands. Research Report No. R662, University of Sydney, 1992.

[7] Brumund WF, Leonards GA. Experimental study of static and dynamic friction between sand and typical construction materials. Journal of Testing and Evaluation 1973, 1 (2): $162-165$.

[8] Yoshimi Y, Kishida T. A ring torsion apparatus for evaluating friction between soil and metal surface. Geot. Testing J. ASTM 1981, 4 (4): 145-152. 
[9] Boutrif A. Mesure du comportement d'interface sol-structure à la boîte de cisaillement direct annulaire et modélisation. Thèse de Doctorat de l'Université Joseph Fourier Grenoble I, Grenoble, 1993.

[10] Uesugi M, Kishida H. Influential factors of friction between steel and dry sands. Soils and Foundations 1986, 26 (2): 33-46.

[11] Fakharian K, Evgin E. An automated apparatus for three-dimensional monotonic and cyclic testing of interfaces. Geot. Testing J. ASTM 1996, 19 (1): 22-31.

[12] Lerat P. Etude de l'interface sol-structure dans les milieux granulaires à l'aide d'un nouvel appareil de cisaillement annulaire. Thèse de Doctorat de l'Ecole Nationale des Ponts et Chaussées, Paris, 1996.

[13] Lerat P, Schlosser F, Vardoulakis I. Nouvel appareil de cisaillement annulaire pour l'étude des interfaces matériau granulaire-structure. Proc. $14^{\text {th }}$ Int. Conf. Soils Mech. and Found. Eng. 1997, vol. 2: 363-366.

[14] Desai CS, Zaman MM, Lightner JG, Sirirwardane HJ. Thin-layer element for interfaces and joints. Int. J. Numer. Anal. Methods Geomech. 1984, 8: 19-43.

[15] Patton FD. Multiple modes of shear failure in rock. Proc. $1^{\text {st }}$ Int. Conference of Rock Mechanics 1966, vol. 1: 509-513.

[16] Ladanyi B, Archambault G. Simulation of shear behaviour of a jointed rock mass. Proc. $11^{\text {th }}$ Int. Symposium on Rock Mech. AIME 1970: 249-260.

[17] Goodman RE, Dubois J. Duplication of dilatancy in analysis of jointed rocks. J. of Soils Mech. and Found. Div. ASCE 1972, 98 (SM4): 399-422.

[18] Ghaboussi J, Wilson EL, Isenberg J. Finite element for rock joints and interfaces. J. of Soils Mech. and Found. Div. ASCE 1973, 99 (SM10): 833-848.

[19] Boulon M, Nova R. Modelling of soil-structure interface behaviour, a comparison between elasto-plastic and rate type laws. Computers and Geotechnics 1990, 9: 21-46.

[20] Gens A, Carol I, Alonso EE. A constitutive model for rock joints: formulation and numerical implementation. Computers and Geotechnics 1990, 9: 3-20.

[21] Desai CS, Fishman KL. Plasticity-based constitutive model with associated testing joints. Int. J. Rock Mech. Min. Sci. and Geomech. Abstr. 1991, 28 (1): 15-26.

[22] Day RA, Potts DM. Zero thickness interface elements. Numerical stability and application. Int. Journ. Num. Anal. Meth. Geomech. 1994, 18: 689-708.

[23] Shahrour I, Rezaie F. An elastoplastic constitutive relation for soil-structure interface under cyclic loading. Computers and Geotechnics 1997, 21: 21-39.

[24] Aubry D, Modaressi A, Modaressi H. A consitutive model fro cyclic behavior of 
interfaces with variable dilatancy. Computers and Geotechnics 1990, 9: 47-58.

[25] Desai CS, Ma Y. Modelling of joints and interfaces using the disturbed-state concept. Int. J. Numer. Anal. Methods Geomech. 1992, 16: 623-653.

[26] Leong EC, Randolph MF. Finite element modelling of rock-socketed piles. Int. J. Numer. Anal. Methods Geomech. 1994, 18: 25-47.

[27] Tejchman A, Tejchman J. Scale effect in pile model tests. Archiwum Hydrotechnicki 1990, XXXVII: 97-126.

[28] Boulon M. Le comportement d'interface sol-structure: aspects expérimentaux et numériques. Rev. Franç. Géotech. 1991, 54: 27-37.

[29] Boulon M, Garnica P, Eissautier M. Simulation numérique 3D du frottement solinclusion en chambre d'étalonnage par équations intégrales aux frontières. Rev. Franç. Géotech. 1995, 73: 36-52.

[30] Poorooshasb HB, Pietruszczak S. On yielding and flow of sand; a generalized twosurface model. Computers and Geotechnics 1985, 1: 33-58.

[31] Sadrnejad SA, Pande GN. A multilaminate model for sands. Proc. Int. Symp. Num. Models in Geomech. (NUMOG III) 1989: 17-27.

[32] Pietruszczak S, Niu X. On the description of localized deformation. Int. J. Numer. Anal. Meth. Geomech. 1993, 17: 791-805.

[33] Bencheikh B. Interaction sol-structure: modélisation et résolution numérique. Thèse de Doctorat de l'Université des Sciences et Techniques de Lille, Lille, 1991.

[34] De Gennaro V, Pande GN. A model for the behaviour of the soil-structure interface. Proc. $4^{\text {th }}$ Europ. Conf. on Num. Meth. in Geotech. Eng (NUMGE98) 1998: 453-462.

[35] Boulon M, Jarzebowski A. Rate-type elastoplastic approaches for soil-structure interface behaviour: a comparison. Proc. Comp. Methods and Adv. in Geomech. 1991: 305-310.

[36] De Gennaro V. Etude du comportement mécanique des interfaces sol-structure. Application à l'analyse du comportement des pieux. Thèse de Doctorat de l'Ecole Nationale des Ponts et Chaussées, Paris, 1999.

[37] Zervos A, Vardoulakis I, Jean M, Lerat P. Numerical investigation of granular interfaces kinematics. Mechanics of cohesive-frictional materials 2000, 5: 305-324.

[38] Hoteit N. Contribution à l'étude du comportement d'interface sable-inclusion et application au frottement apparent. Thèse de Doctorat de l'Institut National Polytechnique de Grenoble, France, 1990.

[39] Tejchman J, Wu W. Experimental and numerical study of sand-steel interfaces. Int. Journ. Num. Anal. Meth.Geomech. 1995, 19: 513-536. 
[40] Zong-Ze Y, Hong Z, Guo-Hua X. A study of deformation in the interface between soil and concrete. Computers and Geotechnics 1995, 17: 75-92.

[41] Schofield AN, Wroth P. Critical state soil mechanics. McGraw-Hill, European Civil Engineering series, London, 1968.

[42] Nova R. On the hardening of soils. Arch. Mech. Stosow. 1977, 29, 3: 435-458.

[43] Fakharian K, Evgin E. Elasto-plastic modelling of stress-path-dependent behaviour of interfaces. Int. Journ. Num. Anal. Meth.Geomech. 2000, 24: 183-199. 


\section{TABLES AND FIGURE CAPTIONS}

Table 1. Physical characteristics of the tested sands

Table 2. Values of the constitutive parameters used for the numerical study of interface tests carried out on a modified direct shear box and C3DSSI apparatus at constant normal stress $(\mathrm{N}=0.55$, for Silica sand $\mathrm{N}=0)$.

Table 3. Values of the constitutive parameters used for the numerical study of interface test between Fontainebleau sand and rough metal plate carried out on a ring simple shear box at constant global volume $(\mathrm{N}=0.55)$.

Fig. 1. Typical mechanical response of the interface

Fig. 2. Yield surface and plastic potential functions

Fig. 3. Evolution of the plastic potential function in the $\sigma_{\mathrm{n}}-\tau$ stress plane

Fig. 4. Evolution of $\mu, \mu_{c}$ and $D$ versus parameter $u_{t}^{p}$

Fig. 5. Comparison of model predictions and experimental results: interface tests at constant normal stress carried out on a modified direct shear box (Fontainebleau sand-rough metal plate $\mathrm{I}_{\mathrm{D}}=0.46$, experimental data from De Gennaro [36])

Fig. 6. Comparison of model predictions and experimental results: interface tests at constant normal stress carried out on a modified direct shear box (Sydney sand-rough metal plate, experimental data from Tabucanon and Airey [6])

Fig. 7. Comparison of model predictions and experimental results: interface tests at constant volume carried out on a ring simple shear box (Fontainebleau sand-rough metal plate, $\mathrm{I}_{\mathrm{D}}=0.49$ )

Fig. 8. Comparison of model predictions and experimental results: interface tests at constant constant normal stress and constant normal stiffness carried out on the C3DSSI apparatus (Silica sand-rough metal plate $\mathrm{I}_{\mathrm{D}}=0.88$, experimental data from Fakharian and Evgin [43]) 


\section{Tables and Figures}

Table 1. Physical characteristics of the tested sands

\begin{tabular}{cccccccc}
\hline Sand & $\gamma_{\mathrm{dmin}}\left(\mathrm{kN} / \mathrm{m}^{3}\right)$ & $\gamma_{\mathrm{dmax}}\left(\mathrm{kN} / \mathrm{m}^{3}\right)$ & $\gamma_{\mathrm{s}}\left(\mathrm{kN} / \mathrm{m}^{3}\right)$ & $\mathrm{e}_{\max }$ & $\mathrm{e}_{\min }$ & $\mathrm{D}_{50}(\mathrm{~mm})$ & $\mathrm{C}_{\mathrm{U}}$ \\
\hline $\begin{array}{c}\text { Fontainebleau } \\
\text { Sidney }\end{array}$ & 13.8 & 17.2 & 26.7 & 0.94 & 0.54 & 0.23 & 1.78 \\
Silica $^{(2)}$ & - & - & 26.5 & 0.84 & 0.54 & 0.30 & 2 \\
\hline
\end{tabular}

Table 2. Values of the constitutive parameters used for the numerical study of interface tests carried out on a modified direct shear box and C3DSSI apparatus at constant normal stress $(\mathrm{N}=0.55$, for Silica sand $\mathrm{N}=0)$.

\begin{tabular}{cccccccccccc}
\hline Sand & $\mathrm{k}_{\mathrm{n}}\left(\mathrm{m}^{-1}\right)$ & $\mathrm{k}_{\mathrm{t}}\left(\mathrm{m}^{-1}\right)$ & $\mu_{\mathrm{o}}$ & $\mu_{\mathrm{f}}$ & $\mu_{\mathrm{r}}$ & $\mu_{\mathrm{co}}$ & $\mathrm{A}$ & $\mathrm{A}_{\mathrm{o}}$ & $\mathrm{B}(\mathrm{m})$ & $\mathrm{u}_{\mathrm{tf}}^{\mathrm{p}}(\mathrm{mm})$ & $\mathrm{t}(\mathrm{mm})$ \\
\hline Fontainebleau & $0.86 \times 10^{5}$ & $0.37 \times 10^{5}$ & 0 & 0.78 & 0.7 & 0.67 & 0.00045 & 4 & 0.05 & $1.410^{-3}$ & 2 \\
\hline Sidney & $0.6 \times 10^{6}$ & $0.3 \times 10^{6}$ & 0 & $0.7 \# 0.96$ & 0.7 & 0.46 & 0.00011 & 20 & 0.08 & $4.710^{-4}$ & 3 \\
\hline Silica & $6 \times 10^{6}$ & $1 \times 10^{6}$ & 0 & 0.81 & 0.6 & 0.49 & 0.00006 & 12 & 0.05 & $4.310^{-4}$ & 6 \\
\hline
\end{tabular}

Table 3. Values of the constitutive parameters used for the numerical study of interface test between Fontainebleau sand and rough metal plate carried out on a ring simple shear box at constant volume $(\mathrm{N}=0.55)$.

\begin{tabular}{cccccccccccc}
\hline Sand & $\mathrm{k}_{\mathrm{n}}\left(\mathrm{m}^{-1}\right)$ & $\mathrm{k}_{\mathrm{t}}\left(\mathrm{m}^{-1}\right)$ & $\mu_{\mathrm{o}}$ & $\mu_{\mathrm{f}}$ & $\mu_{\mathrm{r}}$ & $\mu_{\mathrm{co}}$ & $\mathrm{A}$ & $\mathrm{A}_{\mathrm{o}}$ & $\mathrm{B}(\mathrm{m})$ & $\mathrm{u}_{\mathrm{tf}}{ }^{\mathrm{p}}(\mathrm{mm})$ & $\mathrm{t}(\mathrm{mm})$ \\
\hline Fontainebleau & $0.24 \times 10^{5}$ & $0.14 \times 10^{5}$ & 0 & 0.45 & 0.45 & 0.34 & 0.0003 & - & 0.08 & $510^{-3}$ & 2 \\
\hline
\end{tabular}




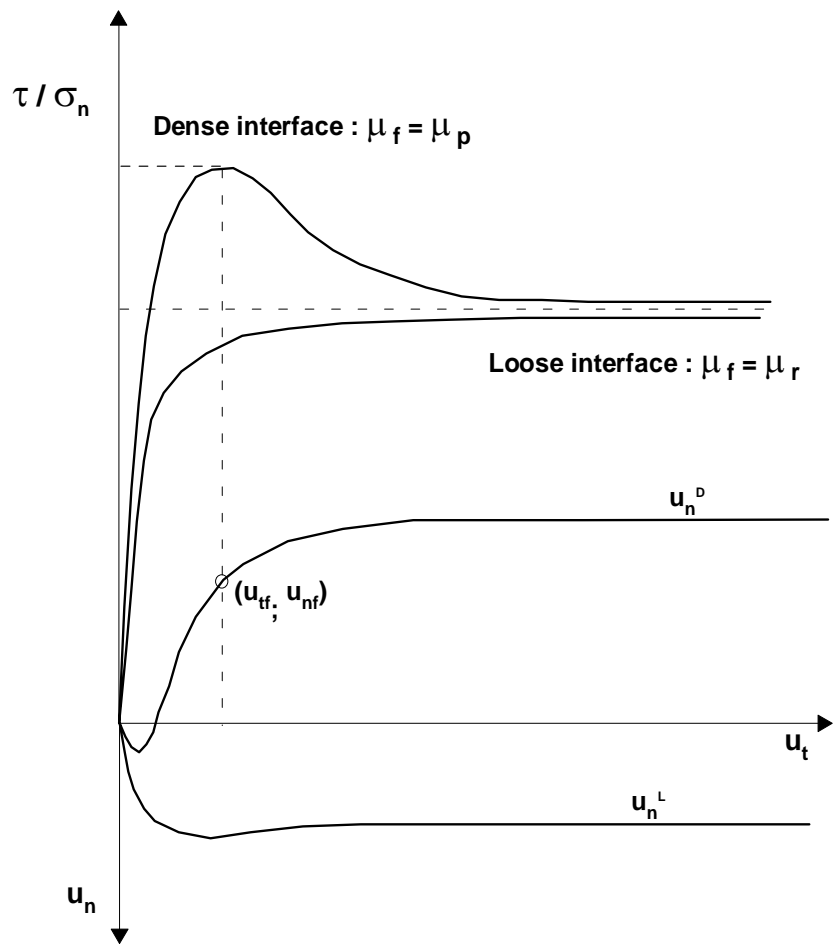

Fig. 1. Typical mechanical response of the interface

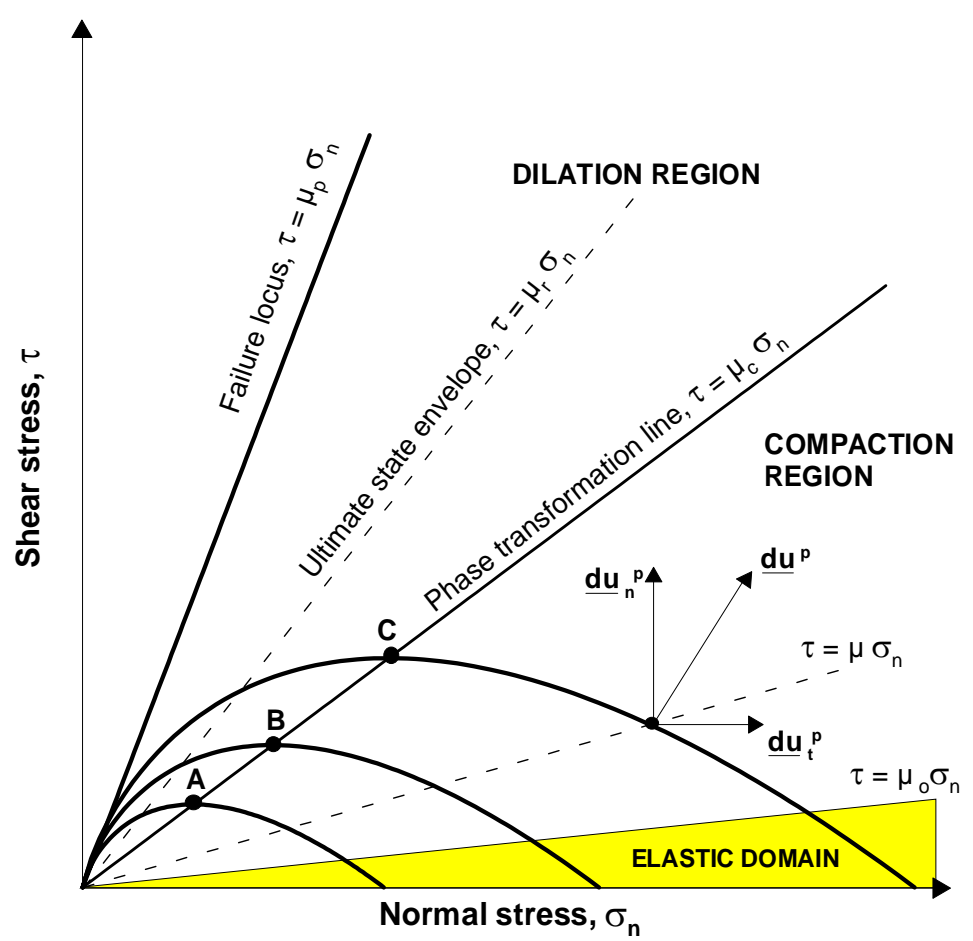

Fig. 2. Yield surface and plastic potential functions 


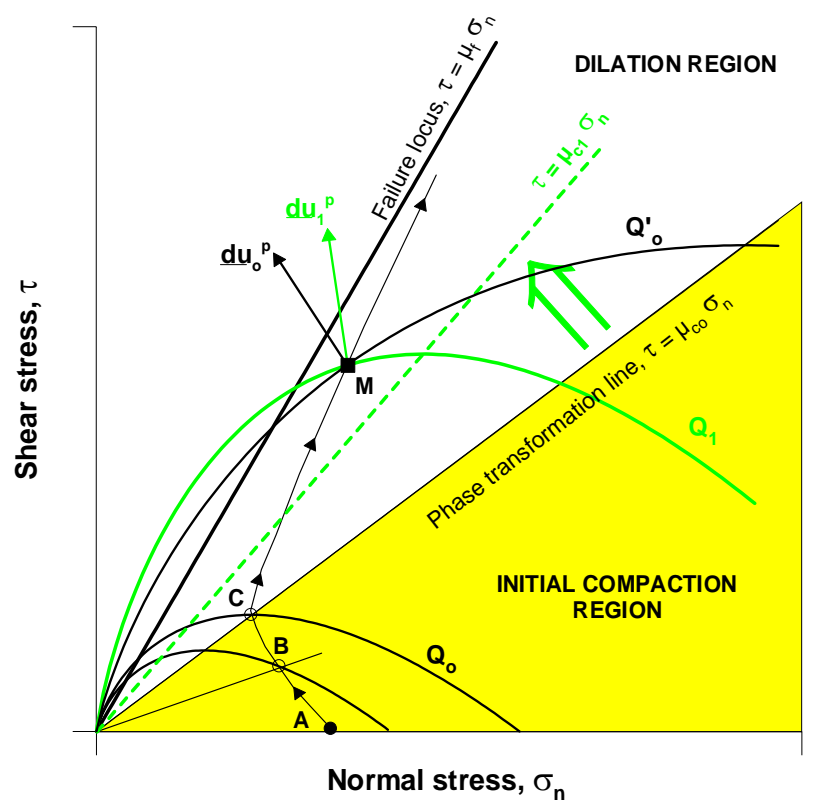

Fig. 3. Evolution of the plastic potential function in the $\sigma_{n}-\tau$ stress plane

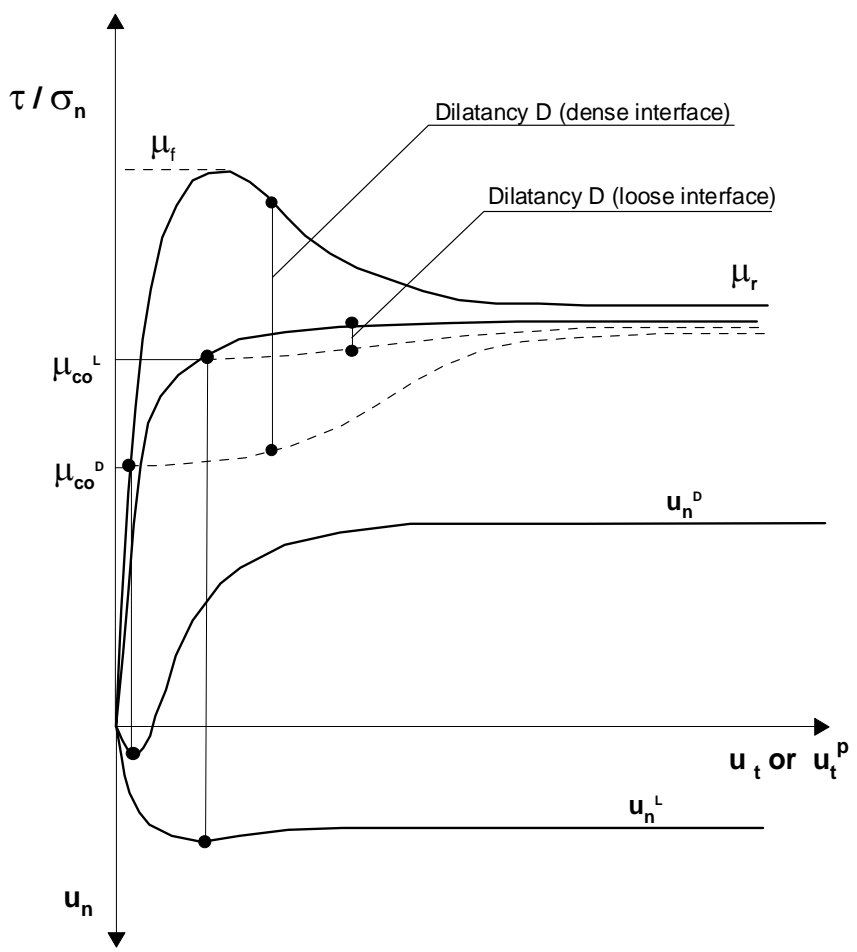

Fig. 4. Evolution of $\mu, \mu_{c}$ and $D$ versus parameter $u_{t}^{p}$ 

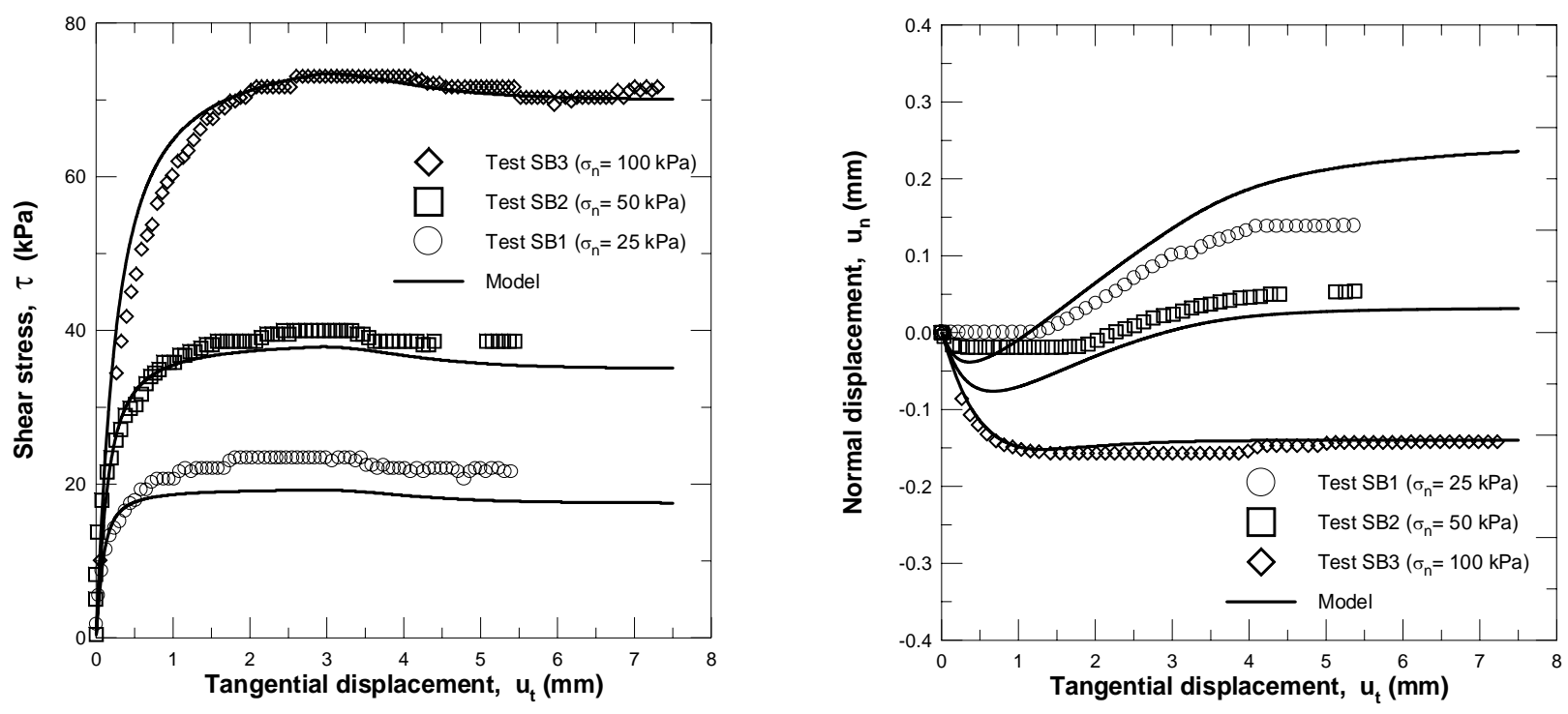

Fig. 5. Comparison of model predictions and experimental results: interface tests at constant normal stress carried out on a modified direct shear box (Fontainebleau sand-rough metal plate $\mathrm{I}_{\mathrm{D}}=0.46$, experimental data from De Gennaro [36])
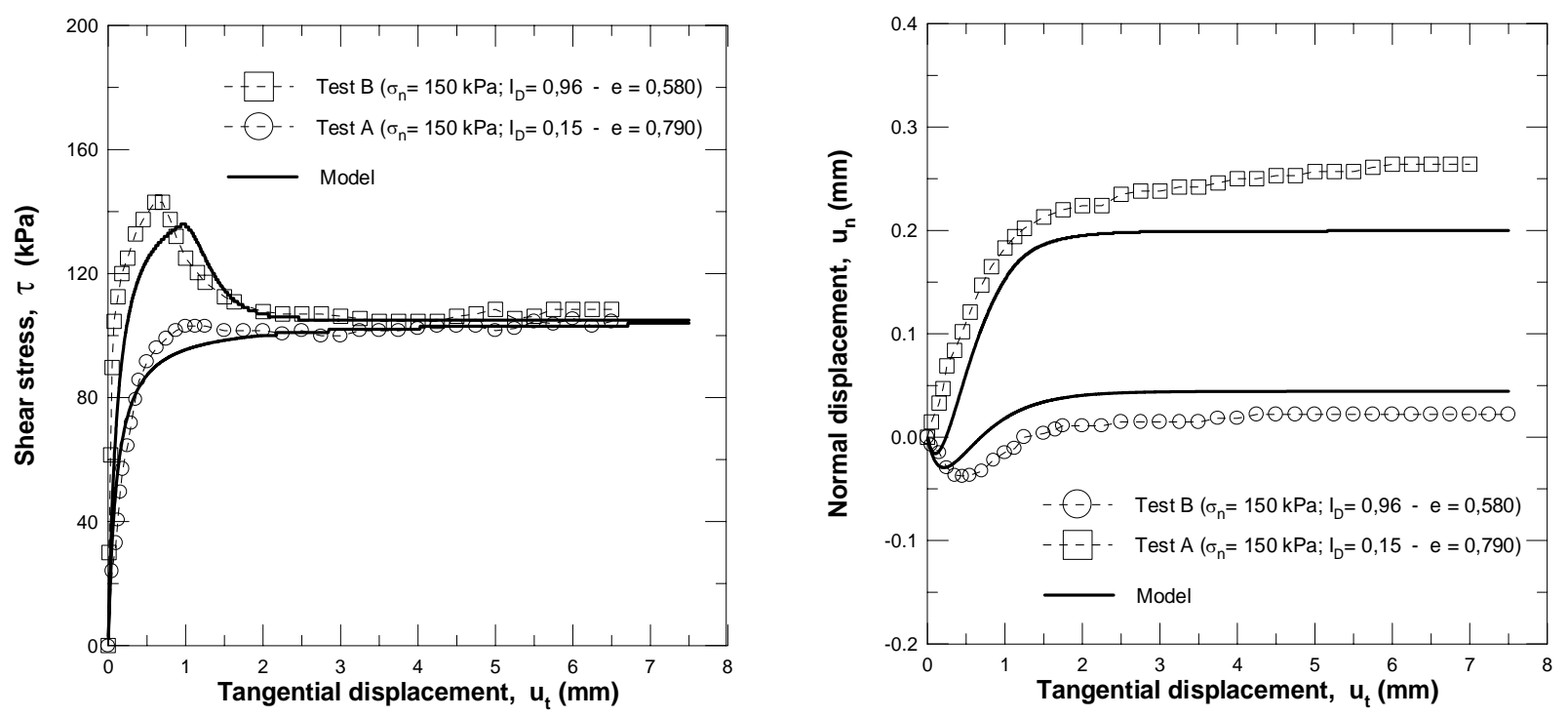

Fig. 6. Comparison of model predictions and experimental results: interface tests at constant normal stress carried out on a modified direct shear box (Sydney sand-rough metal plate, experimental data from Tabucanon and Airey [6]) 


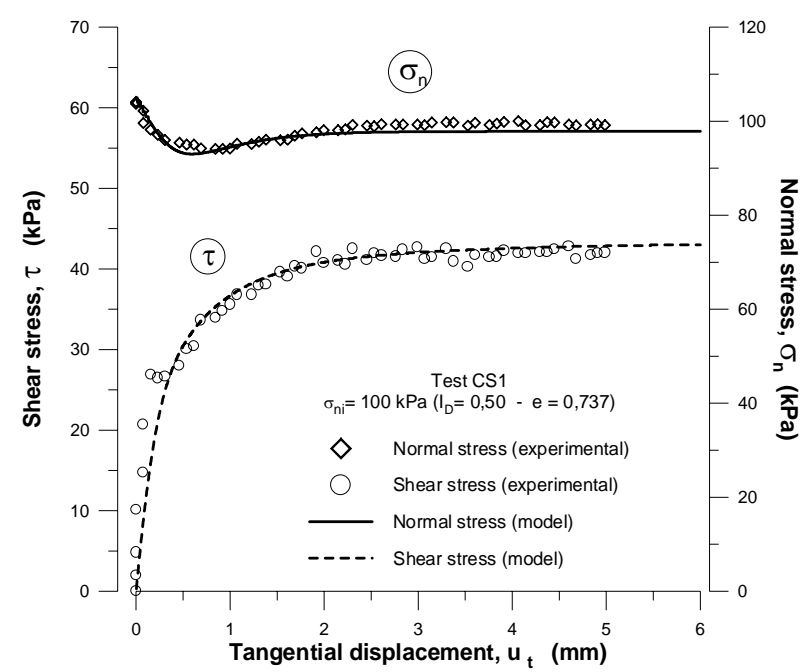

(a)

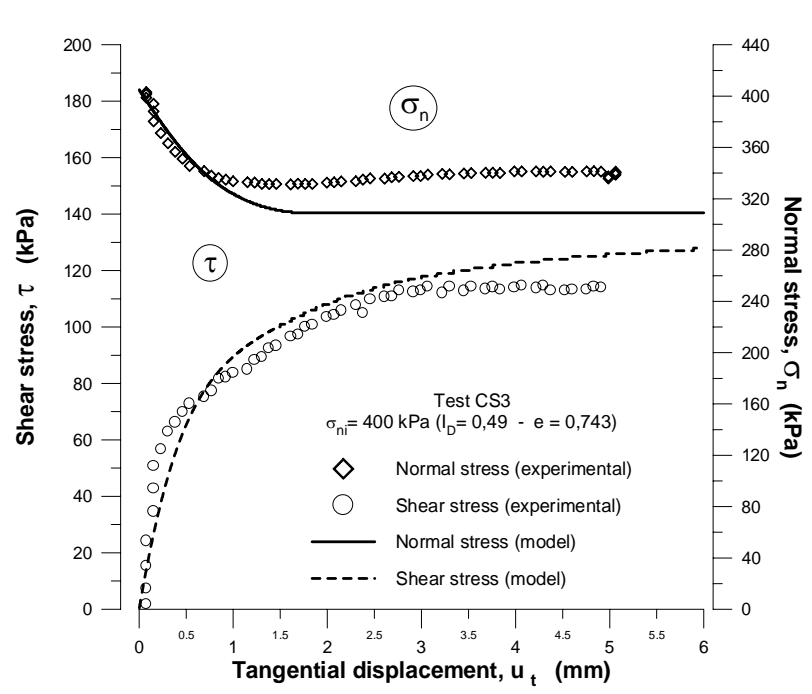

(c)

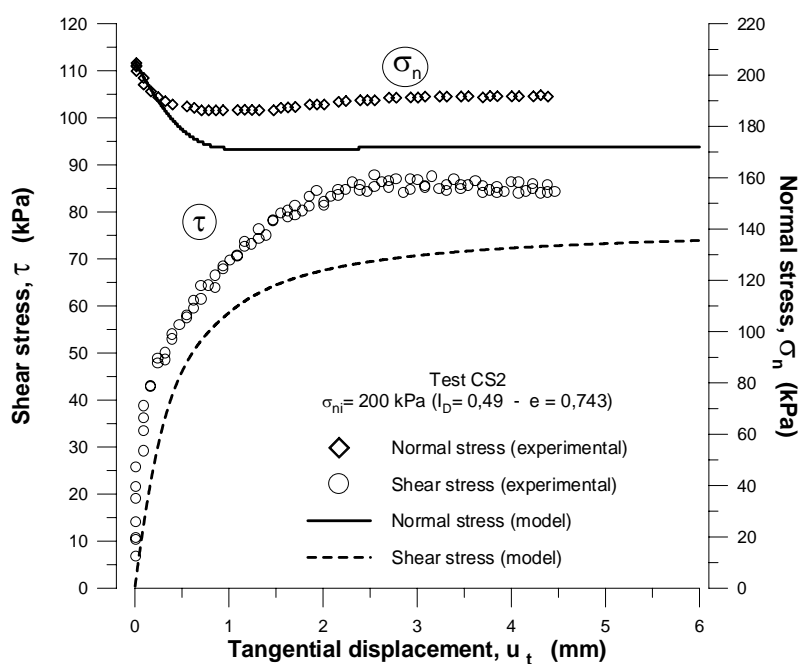

(b)

Fig. 7. Comparison of model predictions and experimental results: interface tests at constant volume carried out on a ring simple shear box (Fontainebleau sand-rough metal plate, $\mathrm{I}_{\mathrm{D}}=0.49$ ) 


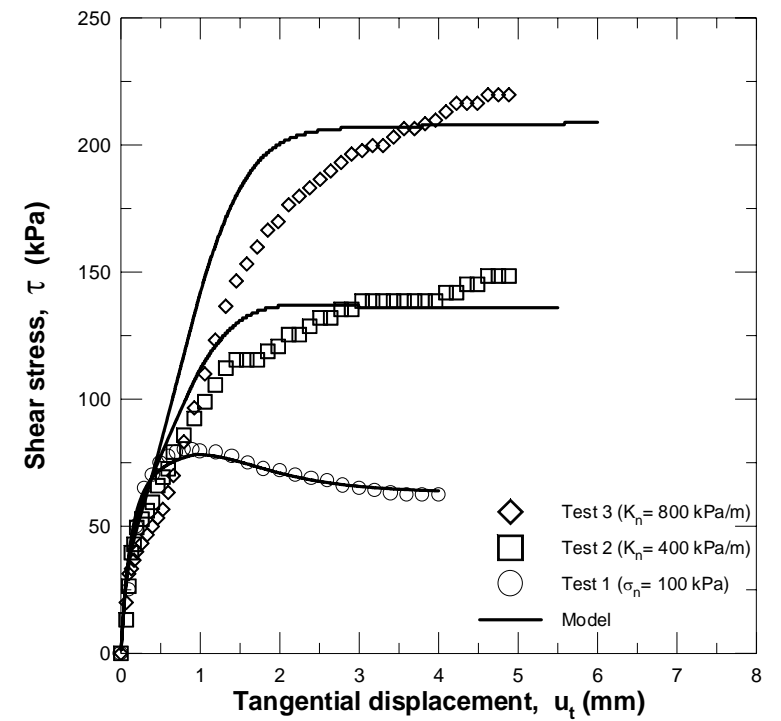

(a)

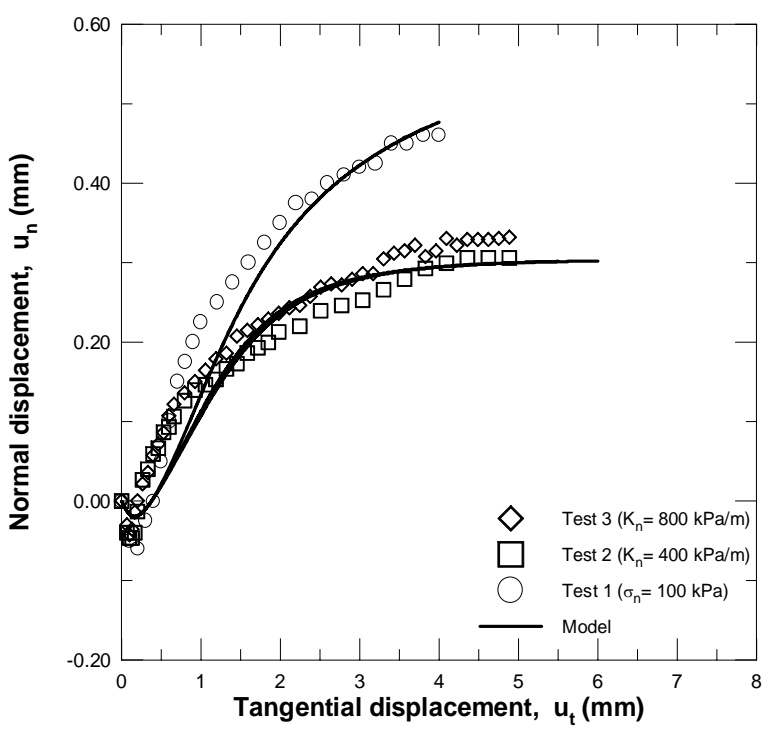

(c)

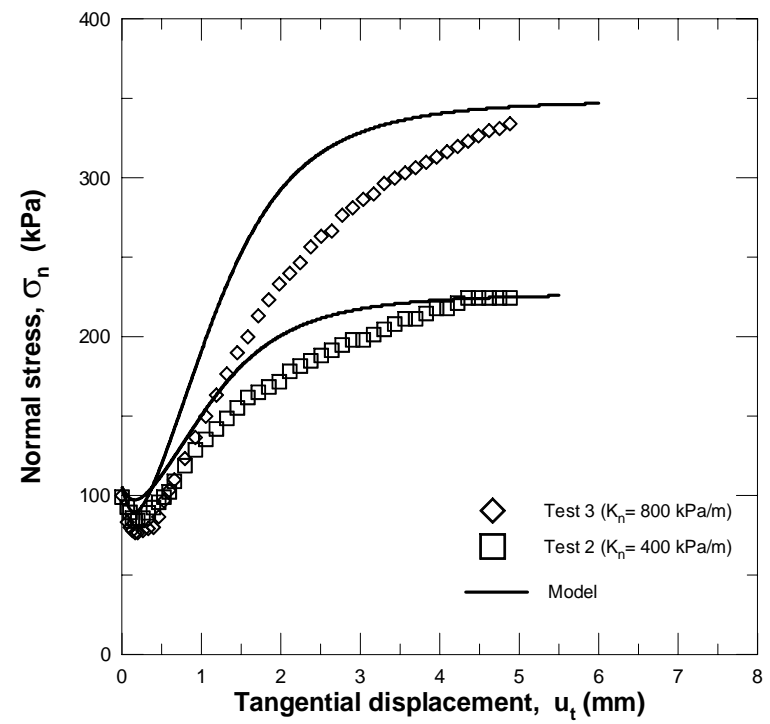

(b)

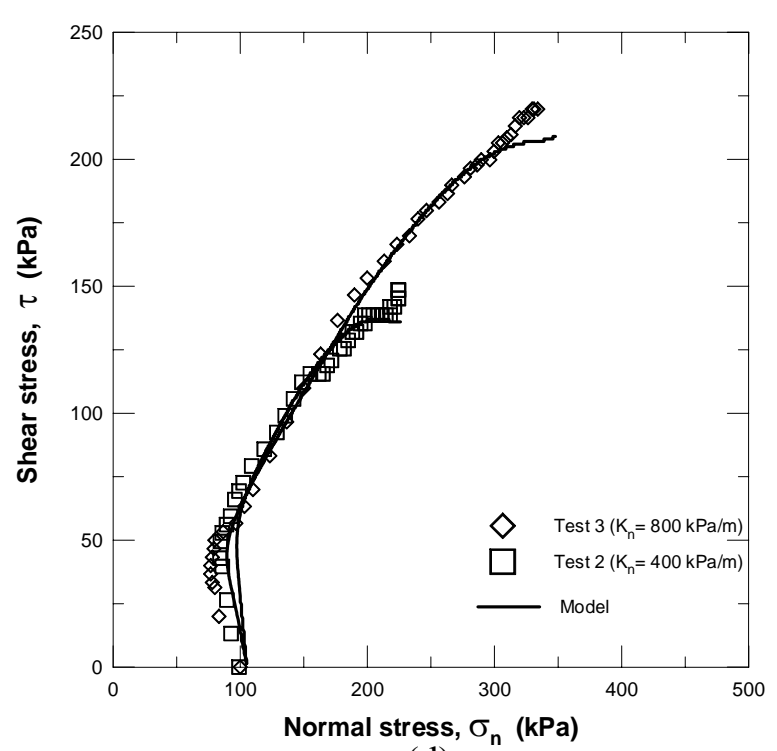

(d)

Fig. 8. Comparison of model predictions and experimental results: interface tests at constant constant normal stress and constant normal stiffness carried out on the C3DSSI apparatus (Silica sand-rough metal plate $\mathrm{I}_{\mathrm{D}}=0.88$, experimental data from Fakharian and Evgin [43]) 